\title{
Relationship between changed alveolar-capillary permeability and angiotensin converting enzyme activity in serum in sarcoidosis
}

\author{
A EKLUND, E BLASCHKE
}

\begin{abstract}
From the Departments of Thoracic Medicine and of Clinical Chemistry, Karolinska Hospital, Stockholm, Sweden
\end{abstract}

ABSTRACT The effect of altered alveolar-capillary permeability on angiotensin converting enzyme (ACE) activity in serum (SACE) was studied in 45 patients with sarcoidosis and 21 healthy controls. In sarcoidosis increased albumin concentrations in the bronchoalveolar lavage fluid (L albumin) and increased ratios of $\mathrm{L}$ albumin to albumin in serum ( $\mathrm{S}$ albumin) indicated an increased permeability of the alveolar-capillary membrane. ACE activity in the lavage fluid (LACE) was correlated with the number of alveolar macrophages in controls, indicating that it may come from these cells. LACE was high in active sarcoidosis while in inactive disease it was similar to that in controls. SACE in sarcoidosis was significantly increased. Ninety per cent of patients with increased L albumin had increased SACE. SACE activity was significantly correlated with concentrations of L albumin and with LACE activity. The relationships between signs of increased membrane permeability and SACE and between LACE and SACE suggest that excess SACE in sarcoidosis may, at least partly, originate in the alveolar space.

In sarcoidosis increased angiotensin converting enzyme (ACE) activity in serum (SACE) have been reported by many authors. ${ }^{1-3}$ The source of this excess activity has not yet been clarified, however.

Angiotensin converting enzyme is known to exist on the luminal surface of endothelial cells in capillaries-for example, in the extensively vascularised normal lung. ${ }^{4}$ Thus increase of SACE could be due to an enhanced production and release from the endothelium during sarcoid inflammation of the lung.

As ACE has been shown immunohistochemically in epithelioid cells of sarcoid granulomas, ${ }^{5}$ these cells have been suggested as the most likely source of excess SACE ${ }^{26}$ although ACE activity has also been found in alveolar macrophages. ${ }^{78}$ Since sarcoidosis is often accompanied by alveolitis with increased numbers of macrophages, possibly the excess SACE also comes from these cells. Previous analyses of ACE activity in bronchoalveolar lavage fluid (LACE) from patients with sarcoidosis have brought discrepant results. Alveolar cells have been reported as showing

Address for reprint requests: Dr Anders Eklund, Department of Thoracic Medicine, Karolinska Hospital, 10401 Stockholm, Sweden.

Accepted 16 December 1985
ACE activity that is greater $\operatorname{than}^{78}$ or similar to that of controls. ${ }^{9}$ In the supernatant Perrin-Fayolle ${ }^{10}$ and Stanislas-Leguern ${ }^{11}$ found raised ACE activity while Brambilla ${ }^{8}$ did not.

We studied the possibility that alveolar macrophages were the source of excess SACE by investigating the relationship between SACE, LACE, and signs of changed alveolar-capillary permeability in inactive and active sarcoidosis. The results were compared with the findings in healthy smokers and non-smokers. Albumin was chosen as indicator of permeability changes because it is believed to pass into the alveolar space by passive transudation from the serum. ${ }^{12}$

\section{Methods}

\section{SUBJECTS}

The subjects consisted of 21 healthy volunteers (14 of them smokers), median age 27 (range 19-53) years, and 45 patients (nine of them smokers) with untreated sarcoidosis, median age 37 (range 25-62) years. In all patients the diagnosis was histologically proved by biopsy specimens from at least one organ or a positive Kveim test result or both.

Twenty two patients had clinically active 
sarcoidosis. They showed progression on their chest radiographs over the previous six months and had one or several of the following symptoms: irritating cough, periods of low grade fever, dyspnoea on effort, a feeling of tiredness previously absent, and a recent weight loss of more than $3 \mathrm{~kg}$.

Chest radiographic grades were: stage $0(n=2)-$ normal radiograph; stage I $(n=2)$-bilateral hilar lymphadenopathy; stage II $(n=25)$-bilateral hilar lymphadenopathy with parenchymal infiltration; stage III $(n=16)$-solely parenchymal infiltration.

Lung volumes were measured by standard spirometry and the helium dilution technique. In controls the median vital capacity was $100 \%$ (range $85-116 \%$ ) and the total lung capacity was $100 \%(81-114 \%)$ of predicted values. ${ }^{13}$ In inactive sarcoidosis the corresponding values were $94 \%(78-122 \%)$ and $93 \%$ (73-115\%) and in active sarcoidosis 83.5\% (59-97\%) and $81 \cdot 5 \%(62-100 \%)$.

\section{BRONCHOALVEOLAR LAVAGE FLUID}

After premedication with morphine and scopolamine, bronchoscopy was carried out with a flexible fibreoptic bronchoscope (Olympus 4B2) under local anaesthesia with $2 \%$ lignocaine. The bronchoscope was wedged in a bronchus in the middle lobe, and sterile saline solution at $37^{\circ} \mathrm{C}$, buffered with sodium

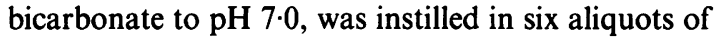
$50 \mathrm{ml}$. An average of $70 \%$ (SD 2\%) of the fluid was recovered in controls and $65 \%(1 \%)$ in patients with sarcoidosis. After each instillation the fluid was gently aspirated and collected in a siliconised plastic bottle placed on ice. The fluid was strained through a double layer of Dacron nets and then centrifuged at $400 \mathrm{~g}$ for five minutes at $4^{\circ} \mathrm{C}$. The supernatant was removed and stored at $-70^{\circ} \mathrm{C}$. Cultures for tuberculous bacilli and fungi were negative in all cases. All subjects gave informed consent.

BRONCHOALVEOLAR LAVAGE FLUID ANALYSIS Supernatants were concentrated by overnight dialysis (cutoff molecular weight 3500 ) against $30 \% \mathrm{w} / \mathrm{v}$ polyethyleneglycol 20000 at $4^{\circ} \mathrm{C}$. The concentration factor was calculated from total protein determinations before and after dialysis. ACE was determined by the spectrophotometric method of Lieberman ${ }^{1}$ and the enzyme activity expressed as $\mathrm{U} / \mathrm{ml}$ of fluid (nmol hippuric acid $/ \mathrm{min} / \mathrm{ml}$ ). To minimise the contribution of unspecific compounds to the absorbance at $228 \mathrm{~nm}$, each sample of extracted hippuric acid was filtered through a separate Durapore filter of $0.22 \mu \mathrm{m}$. The intra-assay and interassay coefficients of variation were $4.1 \%$ and $3.7 \%$.

Total protein was analysed by the method of Bradford, ${ }^{14}$ the commercial Microprotein Rapid Stat Kit being used (Lancer, Irland). The intra-assay and interassay coefficients of variation were $2.9 \%$ and $\overrightarrow{\vec{B}}$ $4.0 \%$. Albumin was determined with a turbidometric $\frac{9}{8}$ immunoassay ${ }^{15}$ using commercial antiserum (Dako- $\frac{\mathrm{C}}{5}$ patts, Denmark) and a lyophilised reference serum of $\frac{\bar{\sigma}}{\bar{N}}$ human origin (Seronorm protein, Nyegaard, Nor- $\frac{\widehat{\Phi}}{\mathrm{D}}$ way) as standard. Intra-assay and interassay coefficients of variation were $2 \%$ and $4 \%$. Total $ळ$ quantities of ACE, albumin, and protein in broncho- $\overrightarrow{0}$ alveolar lavage fluid (LACE, $\mathrm{L}$ albumin, and $\mathrm{L}$ pro- $\overrightarrow{\vec{A}}$ tein respectively) were calculated as products of $\vec{\omega}$ respective concentrations and the total volumes of $\vec{F}$ lavage fluid. The total quantities rather than the concentrations were calculated to minimise the effect $\stackrel{\oplus}{-}$ of fluctuations in recovered volumes. Normal values of the substances were defined as the range of two 용 standard deviations above and below mean values of $\mathrm{O}$ the control group.

The cell pellet was resuspended in $8-10 \mathrm{ml}$ saline. $\vec{\square}$ Aliquots of $50 \mu \mathrm{l}$ were taken for total cell counts, which were made in a Bürker chamber. Smears for $\frac{c}{\infty}$ differential cell counts were prepared by cytocentri- $\vec{\perp}$ fugation at $500 \mathrm{rev} / \mathrm{min}$ for 10 minutes (Cytospin 2, Shandon) and stained with May-Grünwald Giemsa and for naphtol-AS-D-acetate esterase inhibitable by sodium fluoride; $200-500$ cells were counted. The difference between cell counts in the two stains was less than $2 \%$ of the respective percentages.

\section{BLOOD ANALYSIS}

Serum samples were taken on the day of the lavage $\frac{3}{3}$ and stored at $-20^{\circ} \mathrm{C}$. SACE and albumin concentration were measured as described above. The normal values of SACE were $6-32 \mathrm{U} / \mathrm{ml}$, taken as two standard deviations above and below the mean 응 value for 104 people aged $25-50$ years (42 women and $\stackrel{叉}{\times}$ 62 men) studied in a health survey. The normal values $\frac{0}{3}$ of albumin were $37-52 \mathrm{~g} / \mathrm{l}$.

\section{STATISTICAL ANALYSIS}

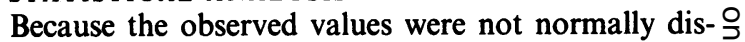
tributed results are given as medians and interquartile $\rightarrow$ ranges, the latter being in parentheses. They were analysed with the non-parametric two tailed Mann- N Whitney test and Spearman's rank correlation coefficient. In the controls, who had normal distributions, Pearson's correlation coefficient was calculated. Proportions were compared by means of the non- - paired, two tailed test of significance of binomiako proportions.

\section{Results}

ANGIOTENSIN CONVERTING ENZYME IN SERUM By comparison with controls (median 18.8 , range $13.3-24.0 \mathrm{U} / \mathrm{ml}$ ), the median value of SACE was 0 
Results of biochemical analysis of bronchoalveolar lavage fluid in controls, in clinically inactive sarcoidosis and in clinically active sarcoidosis (results given as medians and interquartile ranges; groups of inactive and active sarcoidosis compared with the control group and with each other with the Mann-Whitney test)

\begin{tabular}{|c|c|c|c|}
\hline & \multirow[b]{2}{*}{ Controls $n=21$} & \multicolumn{2}{|l|}{ Sarcoidosis } \\
\hline & & Inactive $n=23$ & Active $n=22$ \\
\hline \multirow{2}{*}{$\begin{array}{l}\text { LACE (U in total fluid) } \\
\text { L protein (mg in total fluid) } \\
\text { L albumin (mg in total fluid) } \\
\text { L alb/S alb } \\
\text { LACE } / \text { L albumin } \\
\text { LACE } \times \text { S alb } \\
\text { SACE } \times \text { L alb }\end{array}$} & $\begin{array}{l}95(84-143) \\
14.6(11 \cdot 2-18 \cdot 9) \\
5 \cdot 8(4 \cdot 7-7 \cdot 4) \\
0 \cdot 14(0 \cdot 11-0 \cdot 18) \\
18 \cdot 3(14 \cdot 9-27.5)\end{array}$ & $\begin{array}{l}114 \text { NS }(92-153) \\
17 \cdot 5 \mathrm{NS}(12 \cdot 9-22 \cdot 2) \\
7 \cdot 8^{*}(6 \cdot 3-9 \cdot 4) \\
0 \cdot 20^{*}(0 \cdot 16-0 \cdot 23) \\
13 \cdot 0^{*}(11 \cdot 4-18 \cdot 8)\end{array}$ & $\begin{array}{l}176^{*}(118-231)[*] \\
38 \cdot 2^{* * *}(26 \cdot 2-51 \cdot 7)[* * *] \\
18 \cdot 4^{* * *}(12 \cdot 6-21 \cdot 4)[* * *] \\
0 \cdot 45^{* * *}(0 \cdot 26-0 \cdot 56)[* *] \\
10 \cdot 0^{* * *}(8 \cdot 8-13 \cdot 0)[*]\end{array}$ \\
\hline & $42 \cdot 8(28 \cdot 6-74 \cdot 8)$ & $18 \cdot 0^{* * *}(12 \cdot 2-26 \cdot 1)$ & $9 \cdot 3^{* * *}(8 \cdot 0-14 \cdot 4)[* *]$ \\
\hline
\end{tabular}

L-lavage fluid; $\mathrm{S}$ - serum.

${ }^{* * *}=2 \mathrm{p}<0.001,{ }^{* *}=2 \mathrm{p}<0.01,^{*}=2 \mathrm{p}<0.05$. Significances of comparison between active and inactive sarcoidosis are given in square brackets.

significantly raised $(2 p<0.001)$ both in inactive and in active sarcoidosis, at $30.7(24.3-39.2)$ and 43.7 $(33.4-58.9) \mathrm{U} / \mathrm{ml}$. The increase was more pronounced $(2 p<0.01)$ in clinically active sarcoidosis than in inactive disease. In the control group SACE was slightly higher $(2 p<0.05)$ in non-smokers than in smokers-25.8 (21.7-26.6) and $16(13 \cdot 2-20 \cdot 7) \mathrm{U} / \mathrm{ml}$.

\section{CELLS IN LAVAGE FLUID}

In the lavage fluid the total number of cells (in millions) was similar in controls and in patients with both inactive and active sarcoidosis-namely, 29.7 (23.3-50.3), 22.5 (14.4-35.8), and $25 \cdot 4(20 \cdot 7-32 \cdot 1)$. The percentages of lymphocytes in the three groups were $2 \cdot 7(1 \cdot 4-5 \cdot 2), 14 \cdot 7(10-26 \cdot 2)$, and $21(9 \cdot 4-30 \cdot 7)$, being lower $(2 p<0.001)$ in the controls than in the groups with sarcoidosis. There was, however, no difference between inactive and active sarcoidosis.

Eleven of the 23 patients with inactive disease and 14 of the 22 with active disease had lymphocyte per-

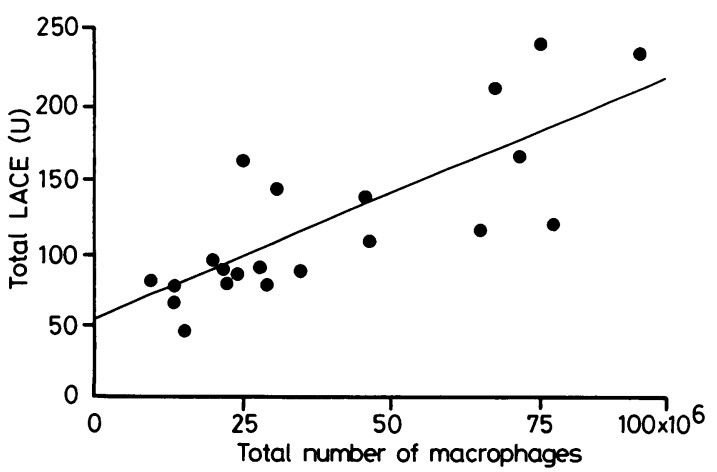

Fig 1 Relationship between total angiotensin converting enzyme activity in lavage fluid ( $L A C E)$ and the total number of alveolar macrophages in bronchoalveolar lavage fluid from controls $(n=21 ; r=0.8, p<0.01)$. centages of total cells more than 2 SD above the control mean value. Thus the proportion of raised lymphocyte percentages was high even in inactive sarcoidosis; it did not significantly differ from that in active disease.

\section{ALBUMIN AND ACE IN LAVAGE FLUID IN CONTROLS}

Data from the control subjects in this study are shown in the table. The total $\mathrm{L}$ protein and total $\mathrm{L}$ albumin of smokers and non-smokers did not differ (16.2 versus $13.7 \mathrm{mg}$ and 6 versus $6.4 \mathrm{mg}$ ).

Within the control group total LACE activity was higher in smokers $(n=14)$ than in non-smokers $(\mathrm{n}=7)-126.5(86 \cdot 3-174 \cdot 3) \mathrm{U}$ and $89(81-112) \mathrm{U}-$ but the difference was not significant. In the controls total LACE activity was significantly correlated with the total number of macrophages (fig 1).

Since this paper was submitted, further analyses of bronchoalveolar lavage fluid from healthy smokers and non-smokers have been carried out. On the basis of all the BAL fluid analysed, total LACE activity was 65 (56-84) $\mathrm{U}$ in 21 non-smoking controls and 127 (87-163) $U$ in 23 smoking controls. This difference was highly significant $(p<0.001)$. A significant correlation between total LACE and the total number of macrophages was again seen in this extended series $(\mathrm{r}=0.71, \mathrm{p}<0.001 ; \mathrm{n}=40)$.

\section{ALBUMIN AND ACE IN LAVAGE FLUID IN SARCOIDOSIS}

Results of the analysis of bronchoalveolar lavage fluid are summarised in the table. The total $\mathrm{L}$ protein was unchanged and both $\mathrm{L}$ albumin and the ratio of $\mathrm{L}$ albumin to $\mathrm{S}$ albumin $(2 \mathrm{p}<0.05)$ were only slightly increased in inactive sarcoidosis but all three indices were increased three to four times in active sarcoidosis $(2 p<0.001$; fig 2$)$.

Angiotensin converting enzyme activity in the total bronchoalveolar lavage fluid (LACE) in inactive sarcoidosis was similar to that observed in controls 


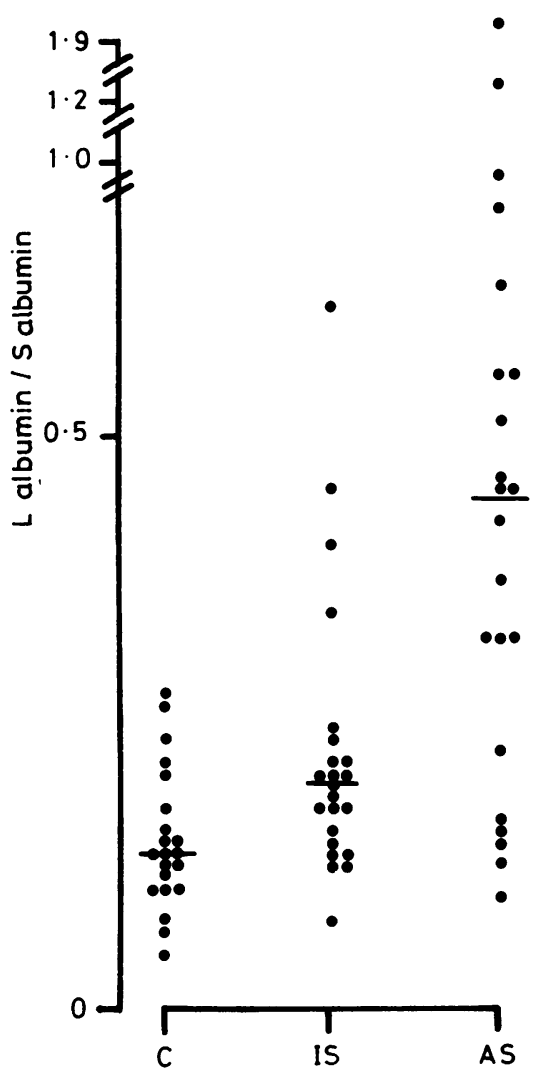

Fig 2 Lavage ( $L$ ) albumin/serum ( $S$ ) albumin ratios in controls $(C, n=21)$ in inactive sarcoidosis $(I S, n=23)$ and in active sarcoidosis ( $A S, n=22)$. Medians are represented by horizontal bars.

but was increased about twofold in active sarcoidosis $(2 p<0.01$; fig 3$)$. There was a decrease in the $\mathrm{LACE} / \mathrm{L}$ albumin ratio in both inactive and active sarcoidosis. No relationship was found between LACE and the total number of macrophages in patients with sarcoidosis.

Frequencies of increased LACE and L albumin more than 2 SDs above the mean control values differed significantly $(p<0.01$ and $p<0.001$ respectively) between inactive and active sarcoidosis. While none of the 23 patients with inactive sarcoidosis had increased LACE, five of the 22 patients with active disease $(27 \%)$ had increased levels. Similarly, only four $(17 \%)$ of those with inactive disease but $17(77 \%)$ of those with active disease had increased $\mathrm{L}$ albumin.

CORRELATIONS BETWEEN SACE, LACE, AND L ALBUMIN

SACE was significantly correlated with LACE in

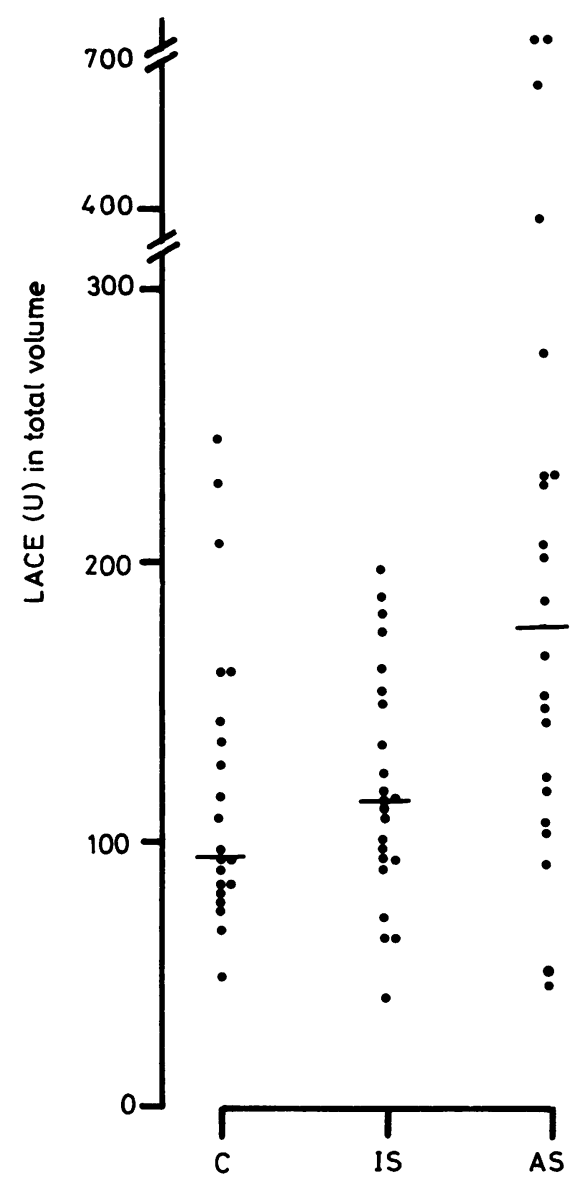

Fig 3 Angiotensin converting enzyme activity in the total bronchoalveolar lavage fluid ( $L A C E$ ) in controls $(C, n=21)$, in inactive sarcoidosis (IS, $n=23)$ and in active sarcoidosis $(A S, n=22)$. Medians are represented by horizontal bars.

inactive $\left(r_{s}=0.43, p<0.05 ; n=23\right)$ as well as in $N$ active sarcoidosis $\left(r_{s}=0.53, p<0.01, n=22\right)$. The correlation was even stronger for the whole group of patients with sarcoidosis $\left(r_{s}=0.53, p<0.001\right.$; $\mathrm{n}=45$ ).

No correlation was found between $L$ albumin and SACE in inactive or in active sarcoidosis. There $\mathbb{D}$ was, however, a significant correlation $\left(r_{s}=0.45,-\right.$ $\mathrm{p}<0.001 ; \mathrm{n}=45$ ) when the coefficient was calculated for all patients together.

Twelve of 13 patients with increased total $L$ albu- $\varrho$ min had increased SACE, and eight of 20 patients $\stackrel{\mathbb{}}{\varrho}$ with normal total $\mathrm{L}$ albumin also had increased SACE. 


\section{Discussion}

The present study was designed to investigate whether sarcoidosis is accompanied by increased permeability of the alveolar capillary membrane as earlier suggested, ${ }^{16}$ and whether such a change affects levels of ACE in serum.

Our findings of increased total $\mathrm{L}$ albumin and increased $\mathrm{L}$ albumin/S albumin ratios in sarcoidosis are in very good agreement with the previous report of Baughman, ${ }^{17}$ who calculated concentrations of albumin in the bronchoalveolar lavage fluid by using methylene blue as a dilution marker. The results suggest an increased alveolar-capillary permeability that may accompany sarcoid alveolitis.

Furthermore, the increase in $\mathrm{L}$ albumin was significantly more pronounced in active sarcoidosis, where alveolitis is probably more intense than in inactive disease. ${ }^{18}$ This makes it conceivable that sarcoid alveolitis might be detected and the degree of inflammation estimated by the amount of total albumin in the lavage fluid. Furthermore, since total $\mathrm{L}$ albumin exceeds the control values in most patients with active sarcoidosis it might even be a better indicator of the intensity of the alveolitis than the percentage of bronchoalveolar lavage fluid lymphocytes. Lymphocyte percentages were high both in inactive and in active sarcoidosis, showing no significant increase with disease activity; and increased numbers of lymphocytes did not become more frequent with disease activity.

In the present study patients with sarcoidosis showed significantly increased SACE, especially in the presence of active disease. A possible source of increased SACE could be the endothelial cell damaged by the inflammatory process. Angiotensin converting enzyme has been shown to be increased both in bronchoalveolar lavage fluid and in serum in rats treated with agents toxic for the endothelium, such as bleomycin $^{19}$ and thiourea. ${ }^{20}$ Extensive studies on SACE, however, in various inflammatory lung diseases, where the endothelial cell is likely to be damaged, have rarely shown increased serum levels. ${ }^{21}$

In sarcoidosis the excess SACE may originate, at least partially, in sarcoid granulomas ${ }^{2} 56$ within the lung and in extrathoracic locations. This could be the case especially in those of our patients who showed normal $L$ albumin but raised SACE. We believe, however, that our results indicate that alveolar macrophages could be another source of excess SACE in patients with sarcoidosis with increased permeability, for three reasons. Firstly, we found strong evidence for a relationship between LACE and the number of alveolar macrophages in healthy persons, suggesting although not proving that LACE may originate in these cells. This is supported by previous reports of ACE within alveolar macrophages. ${ }^{7822}$ Secondly, we found a close relationship between excess SACE in sarcoidosis and signs of increased membrane permeability (as measured by total $\mathrm{L}$ albumin and $\mathrm{L}$ albumin/S albumin ratios). Almost all of our patients with increased total $\mathrm{L}$ albumin had high SACE. Furthermore, in the whole group of patients with sarcoidosis SACE and L albumin were correlated. We found no direct correlation, however, between total $\mathrm{L}$ albumin and SACE in inactive or active sarcoidosis per se. A possible explanation might be variability of macrophage activation and hence secretion of ACE in sarcoidosis, with large variations in LACE as seen in active disease (fig 1). SACE levels affected by both changed permeability and varying degree of macrophage activation would not necessarily show a direct correlation with $L$ albumin. Similar factors may affect LACE, which would explain why no correlation existed between LACE and the number of macrophages in sarcoidosis.

On the other hand, in healthy smokers with an intact membrane as indicated by low $\mathrm{L}$ albumin and low $\mathrm{L}$ albumin/S albumin ratios, SACE levels were normal despite high LACE. The findings suggest that membrane permeability is an important factor affecting levels of SACE. It offers, however, no clues concerning the origin of normal SACE activity in healthy persons. Our observation of higher SACE levels in non-smokers than in smokers makes macrophages an unlikely source of normal SACE activity. Thirdly, we found a highly significant correlation between levels of SACE and LACE both in inactive and in active sarcoidosis, suggesting that the lung space washed by bronchoalveolar lavage fluid may be a source of SACE. Direct evidence, firstly, for the origin of ACE in alveolar macrophages and, secondly, for its flow from the alveolar to the capillary space in sarcoidosis is, however, lacking. To find an answer to the first question, studies in cell cultures are in progress in our laboratory. Possibly, intra-alveolar application of labelled ACE followed by its analysis in serum could provide evidence for the second.

In conclusion, we suggest that in sarcoid alveolitis the permeability of the membrane increases, allowing more albumin to diffuse from serum to the alveolar space and, possibly, ACE to diffuse in the opposite direction. If ACE diffused from serum to the alveolar space concomitantly with albumin then the LACE $\times \mathrm{S}$ albumin/SACE $\times \mathrm{L}$ albumin ratio would not differ between controls and patients with sarcoidosis, whereas it did differ in our observations. On the other hand, if ACE is produced in the alveolar space and the membrane permeability is increased the ratio would decrease in sarcoidosis. This is in agreement with our findings. 
We thank Bengt Danielsson for excellent technical assistance. Grant support by the Swedish National Association Against Heart and Chest Diseases is gratefully acknowledged.

\section{References}

1 Lieberman J. Elevation of serum angiotensin-converting enzyme (ACE) level in sarcoidosis. Am J Med 1975;59:365-72.

2 Silverstein E, Friedland J, Lyons HA, Gourin A. Elevation of angiotensin-converting enzyme in granulomatous lymph nodes and serum in sarcoidosis: clinical and possible pathogenic significance. Ann $N Y$ Acad Sci 1976;278:498-513.

3 Rohatgi PK. Serum angiotensin-converting enzyme in pulmonary disease. Lung 1982;160:287-301.

4 Ryan JW, Ryan US, Schultz DR, Whitaker C, Chung A, Dorer FC. Subcellular localization of pulmonary angiotensin-converting enzyme (kininase II). Biochem $J$ 1975;146:497-9.

5 Silverstein E, Pertschuk LP, Friedland J. Immunofluorescent localization of angiotensin-converting enzyme in epithelioid and giant cells of sarcoidosis granulomas. Proc Natl Acad Sci 1979;76:6646-48.

6 Fanburg BL. Serum angiotensin-1-converting enzyme in the diagnosis and determination of activity of sarcoidosis. In: Fanburg BL, ed. Sarcoidosis and other granulomatous disorders. New York, Marcel Dekker, 1983:263-72.

7 Hinman LM, Stevens C, Matthy RA, Gee JBL. Angiotensin convertase activities in human alveolar macrophages: Effects of cigarette smoking and sarcoidosis. Science 1979;205:202-3.

8 Brambilla C, Chavez L, Brambilla E, et al. Prognostic value of bronchoalveolar lavage and angiotensin converting enzyme in sarcoidosis. In: Chretien J, Marsac I, Saltiel IC, eds. Proceedings of the ninth international conference on sarcoidosis and other granulomatous disorders. Paris: Pergamon Press, 1981:419-23.

9 Gupta RG, Sicilian L, Catchatourian R, Bekerman C, Oparil S, Szidon JP. Angiotensin-converting enzyme in serum and in bronchoalveolar lavage in sarcoidosis. Respiration 1982;43:153-7.

10 Perrin-Fayolle M, Pacheo Y, Harf R, Montagnon B, Biot N. Angiotensin converting enzyme in bronchoalveolar lavage fluid in pulmonary sarcoidosis. Thorax
1981;36:790-2.

11 Stanislas-Leguern G, Leclerc P, Baumann FC, et al. Angiotensin converting enzyme in bronchoalveolar fluid and serum as indicators of spread of untreated sarcoidosis. In: Chretien J, Marsac I, Saltiel IC, eds. Proceedings of the ninth international conference on sarcoidosis and other granulomatous disorders. Paris: Pergamon Press, 1981:356-61.

12 Stockley RA. Measurement of soluble proteins in lung secretions. Thorax 1984;39:241-7.

13 Berglund E, Birath G, Bjure J, et al. Spirometric studies in normal subjects I. Acta Med Scand 1963;173: 185-92.

14 Bradford MM. A rapid and sensitive method for the quantitation of microgram quantities of protein utilizing the principles of protein-dye binding. Anal Biochem 1976;72:248-54.

15 Bergström K, Lefvert AK. An automated turbidometric immunoassay for plasma proteins. Scand J Clin Lab Invest 1980;40:637-40.

16 Mordelet-Dambrine MS, Stanislas-Leguern GM Huchon GJ, Baumann FC, Marsac JH, Chretien J. Elevation of the bronchoalveolar concentration of angiotensin converting enzyme in sarcoidosis. Am Rev Respir Dis 1982;126:472-5.

17 Baughman RP, Bosken CH, Loudon RG, Hurtubise P, Wesseler T. Quantitation of bronchoalveolar lavage with methylene blue. Am Rev Respir Dis 1983;128:266-70.

18 Crystal RG, Roberts WC, Hunninghake GW, Gadek JE Fulmer JD, Line BR. Pulmonary sarcoidosis: a disease characterized and perpetuated by activated lung T-lymphocytes. Ann Intern Med 1981;94:73-94.

19 Newman RA, Kimberly:PJ, Stewart JA, Kelley J. Assessment of bleomycin lung toxicity using angiotensinconverting enzyme in pulmonary lavage. Cancer Res 1980;40:3621-6.

20 Hollinger MA, Giri SN, Patwell S, Zuckerman JE, Gorin A, Parsons G. Effect of acute lung injury on angiotensin-converting enzyme in serum, lung lavage and effusate. Am Rev Respir Dis 1980;121:373-6.

21 Rømer FK. Clinical and biochemical aspects of sarcoidosis. Acta Med Scand 1983; suppl 690:52-61.

22 Takada Y, Hiwada $\mathrm{K}$, Akutsu $\mathrm{H}$, Hashimoto A, Kokubu T. The immunocytochemical detection of angiotensin-converting enzyme in alveolar macrophages from patients with sarcoidosis. Lung 1984;162:317-23. 